\title{
A TEN-YEAR TEST FOR TRANSPLANTED WHLD BLACK AND RED SPRUCE
}

\author{
BY G. L. BASKERVILLE ${ }^{1}$
}

\begin{abstract}
Wild black and red spruce seedlings were lifted at the Acadia Forest Experiment Station and planted at Green River, New Brunswick in 1950. By 1960 survival averaged 38 per cent for the two species and they had reached an average height of six feet.

The current interest in using wild stock for planting prompts the following report. In the spring of 1950 , one thousand seedlings of black spruce (Picea mariana) and red spruce $(P$. rubens) were lifted from a wet peaty site on the Acadia Forest Experimental Station (N. Lat. $46^{\circ} 00$ W. Long. $66^{\circ} 20$; altitude about 200 feet) and transferred to the Green River watershed in

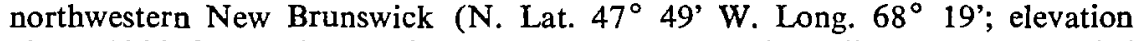
about 1900 feet). The species were not separated, but all stock was graded into two size-groups: 5-10 inches, and 11-15 inches in height.

The planting site is on a hilltop with less than 5 per cent slope and a northwesterly aspect. The soil is a shallow, stony, dumped till, 6 to 10 inches deep and of a silt-loam texture, overlying a strongly fractured, steeply dipping slate. Prior to logging in 1947, it supported an overmature mixedwood stand of about 15 cords of softwood pulpwood per acre.

The one-acre plot was divided into eight compartments of which four were planted with the 5- to 10-inch seedlings and four with the 11- to 15-inch seedlings. Planting was by the hole method at a 6- by 6-foot spacing.

There were few shrubs in 1950 although pin cherry, raspberry, and mountain maple had increased since logging. By 1953, the shrubs had closed in around the spruce; it was decided to release one-half the stems. Inadvertently, the entire plot was sprayed with a heavy dose of herbicide killing all shrubs and a few spruce. By 1960, the softwoods stood well above their competition (Figure 1).

Most of the mortality occurred in the first three years (especially where seedlings were not sheltered by shrub growth) and, by 1960,38 per cent of the larger and 39 per cent of the smaller stock were still living (Table 1). This might be compared roughly with 83 per cent survival obtained with nursery-grown white spruce seedlings over a six-year period on similar sites (McLeod 1961)..$^{2}$
\end{abstract}

\footnotetext{
${ }^{I}$ Research Officer, Maritimes District Office, Forest Research Branch, Department of Forestry, Fredericton, N.B.

${ }^{2}$ McLEOD, J. W. 1961. Planting white spruce on haul roads in northwestern New Brunswick. Canada Department of Forestry, Forest Research Branch, Mimeo 61-20, 4 pp. Sec plantations $G_{1}, G_{2}$ and $H$.
} 
TABLE 1

Survival And Total Height In 1960 Of Natural Black And Red Spruce Seedlings Planted In 1950

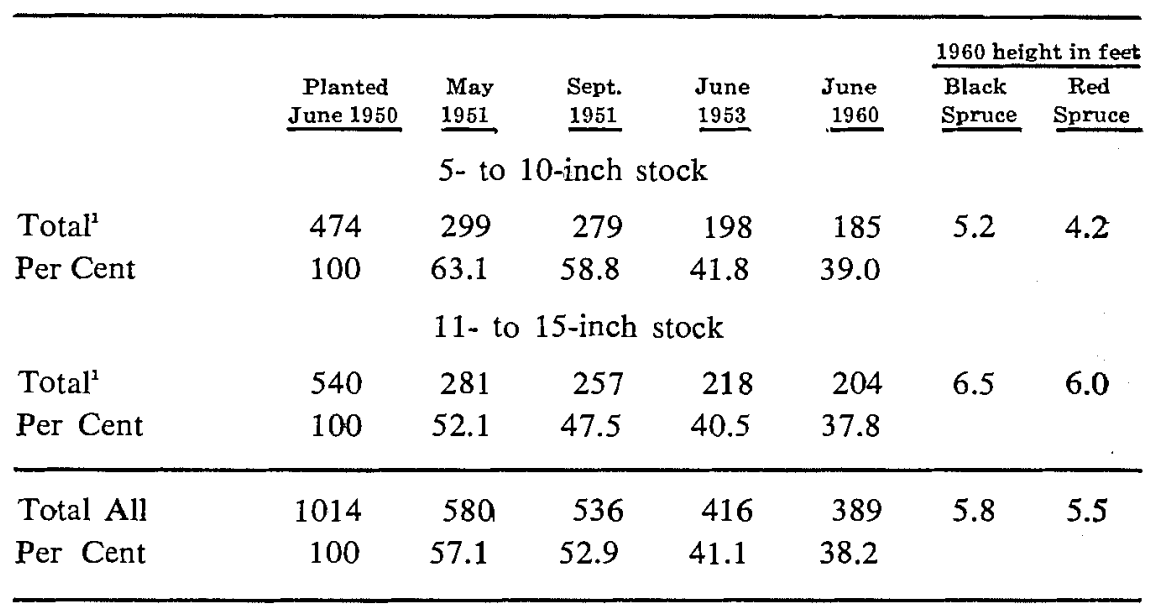

${ }^{1}$ Total for the four subplots in each size class.

The two spruces were readily distinguishable in 1960 when the proportions were found to be 96 per cent black spruce and 4 per cent red spruce in the original 5- to 10 -inch group, and 88 per cent black and 12 per cent red in the 11- to 15-inch group. Because the species were not determined at the time of planting, the preponderance of black spruce among the survivors is not to be interpreted as a differential in survival between black and red spruce. The black spruce averaged 6.5 feet in total height in 1960 for the larger group and 5.2 for the smaller; the red spruce averaged 6.0 and 4.2 feet in the respective groups.

In summary, this planting indicates that wild black spruce and red spruce can be moved and planted with fair success. When released from competition, the survivors are able to grow rapidly, the black spruce being slightly superior to the red spruce. 


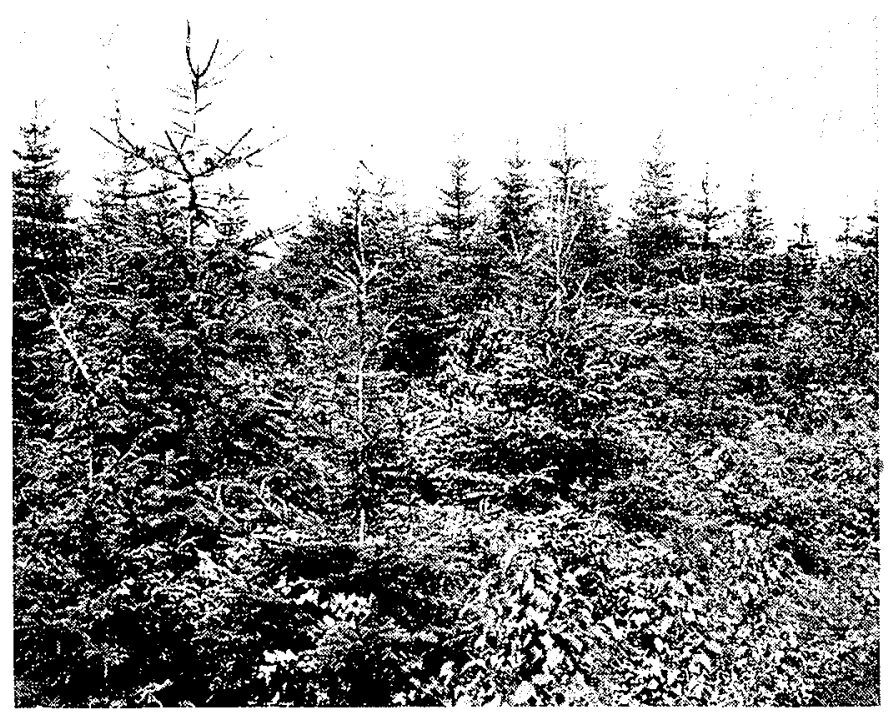

FIGURE 1. Black spruce planted in 1950. Note the absence of shrub competition. 

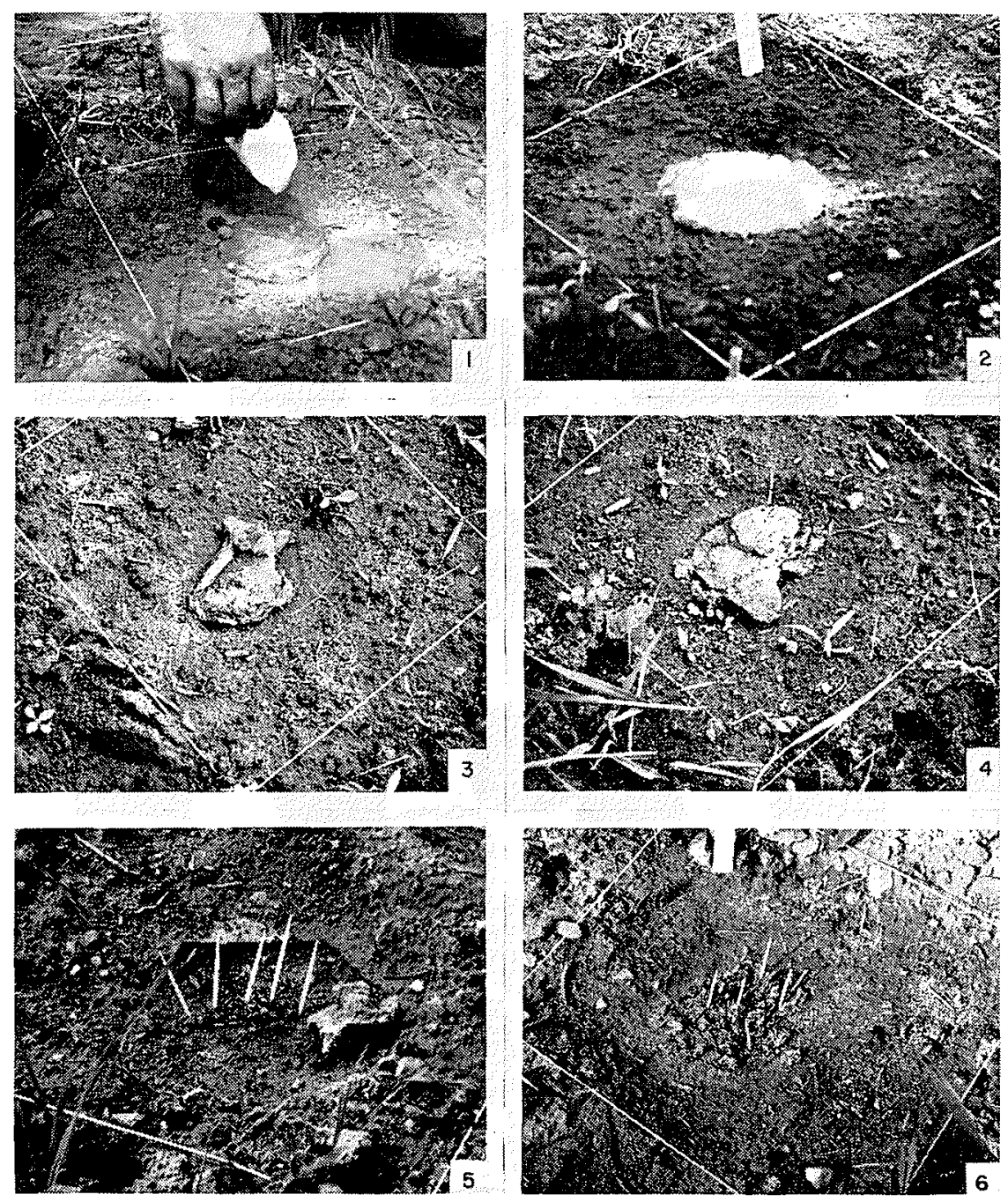

FIGURES 1-6 Keltex behaviour on seed spots: 1. Application. 2. Three days later. 3. Drying out. 4. Lifting by seedlings. 5. Rolls free from seedlings. 6. Continuously moist mulch. 